\title{
Avaliação dos custos econômicos associados aos jovens nem-nem no Brasil
}

\author{
Evaluation of the economic costs \\ associated to the neet youth in Brazil
}

\author{
MAITÊ RIMEKKÁ SHIRASU* \\ RONALDO DE ALBUQUERQUE E ARRAES**
}

\begin{abstract}
RESUMO: A existência de milhões de jovens que nem estudam nem trabalham, os denominados nem-nem, tem implicações danosas para a sociedade e para a economia. Este estudo foca nos principais custos econômicos associados à ociosidade desses jovens por meio do Propensity Score Macthing. Os resultados revelam que os jovens nem-nem representaram um custo de $0,6 \%$ do PIB em 2015. Considerando esse significante custo anual, e a trajetória crescente desse contingente juvenil nos últimos anos, há que se clamar pela implementação de políticas que contenham esse crescimento, a fim de se evitar severos prejuízos de ordem econômica e social no longo prazo.
\end{abstract}

PALAVRAS-CHAVE: Jovens nem-nem; custos econômicos; avaliação de política.

ABSTRACT: The existence of millions of youths remain in the NEET status brings severe implications for the society and for the economy. Thus, this paper focuses on the main costs associated with the neet youth idleness through the Propensity Score Matching. The results reveal that the neet youths accounted for a cost of $0.6 \%$ of the GDP in 2015. Considering this significant annual cost and the increasing amount of neet youths in the last years, there is to be claimed for policies that hinder such a growing path in order to avoid severe economic and social losses in the long run.

KEYWORDS: Neet youth; economic costs; policy evaluation.

JEL Classification: E24; I28; J17; J18; C54.

\footnotetext{
* Economista do quadro da Universidade Federal do Ceará - UFC. E-mail: maiteshirasu@ufc.br. Orcid: 0000-0001-6243-5243.

* Professor do Programa de Pós-Graduação em Economia e do Programa de Economia Profissional da Universidade Federal do Ceará - UFC . E-mail: ronald@ufc.br; ronaldo@caen.ufc.br. Orcid: 00000001-8504-646X. Submetido: 8/Janeiro/2018; Aprovado 17/Julho/2019.
} 


\section{INTRODUÇÃO}

A transição dos jovens da escola para o mercado de trabalho não segue necessariamente um caminho único, mas, sim, trajetórias diversas cercadas de particularidades, perpassando o recorrente fenômeno da evasão escolar, razão pela qual os indicadores tradicionais que buscam analisar a vulnerabilidade dos jovens no mercado de trabalho têm se tornado insuficientes. Em vista disso, tem crescido nas últimas duas décadas a importância de estudos que abordam o status nem-nem dos jovens (nem estudam nem trabalham), apontando diversas vulnerabilidades sociais e econômicas associadas a eles (Balan, 2016).

Entre essas vulnerabilidades estão o desemprego e o abandono precoce da escola, além do desencorajamento dos jovens para o mercado de trabalho. Assim, o conceito nem-nem inclui grupos bem distintos, alguns com possibilidade de levar desvantagens de longo prazo e outros que estão nessa condição apenas temporariamente, elevando o número de potenciais nem-nem. Entre esses, os principais afetados são os com mais baixo nível educacional, cuja probabilidade de pertencerem ao grupo dos nem-nem é três vezes maior do que os jovens com ensino superior (Eurofound, 2012).

Ao contrário do que se pode imaginar, o problema dos nem-nem não está relacionado apenas às deficiências de oferta no mercado de trabalho, mas, como aponta Coles et al. (2010), é também resultado de uma mudança do lado da demanda, uma vez que o mercado de trabalho foi se transformado em resposta às mudanças ocorridas no ensino superior. Isso tem como resultado a preferência dos empregadores por recrutar estudantes universitários para cumprir meia jornada a jovens recém-egressos do ensino médio para trabalhos em tempo integral. Os jovens, por sua vez, veem nesses empregos oportunidades para auferir renda no curto prazo, porém, sem vislumbrar sua permanência nessa ocupação.

Além disso, a melhoria dos níveis educacionais tem incentivado os jovens a almejar melhores empregos, aumentando o salário reserva, e, assim, uma parcela deles optam por buscar uma melhor qualificação antes de entrar no mercado de trabalho. Segundo Venturi e Torini (2014), em 2013 36\% dos jovens brasileiros de 15 a 29 anos economicamente inativos não procuravam emprego porque estavam estudando e, entre os que estavam desempregados, $24,1 \%$ rejeitaram o emprego encontrado devido à baixa remuneração oferecida $(31 \%)$, seguida dos fatos de que o trabalho não era interessante e de que o local não era conveniente.

A transição mais longa escola-trabalho na juventude tem diversas consequências negativas para o indivíduo no longo prazo, tais como: precariedade dos postos de trabalho, baixa remuneração, alto grau de informalidade, elevada taxa de rotatividade (dobro da taxa dos adultos (Corseuil et al., 2013)). Tudo isso pode afetar a saúde física, emocional e psicológica dos jovens, além de implicar menores ganhos com aposentadoria no futuro, o que pode ter repercussões intergeracionais.

Tendo em vista as consequências sociais e econômicas atribuídas ao fenômeno dos nem-nem, alguns estudos no âmbito internacional estimaram os custos econô- 
micos a ele associados (Godfrey et al., 2002; Coles et al., 2010; Eurofound, 2012; Pacheco e Dye, 2014). Resultados obtidos pela Eurofound (2012), por exemplo, revelaram perdas econômicas correspondentes a 1,2\% do PIB europeu e superando $2 \%$ em alguns países.

No Brasil, não obstante o aumento do acesso à educação em todos os níveis de ensino nos últimos anos, que levou a um aumento contínuo nos anos de estudo, ainda existem 7,2 milhões de jovens de 15 a 24 anos que nem estudam nem trabalham, conforme dados da PNAD 2015. A despeito dos elevados custos dos nem-nem identificados em vários países, no Brasil ainda são incipientes os trabalhos com esse propósito.

Nesse sentido, o objetivo deste estudo é inferir sobre a perda econômica para o Brasil decorrente da ociosidade dos jovens, de modo a aquilatar sua reversão para benefícios econômicos e sociais que adviriam do reengajamento no sistema educacional e/ou no mercado de trabalho. Para tanto, propõe-se estimar os custos enfrentados pela sociedade ao não integrar uma parcela significativa dos jovens no mercado de trabalho e na educação, projetando a perda de produtividade, medida em salários não ganhos, e o custo esperado para as finanças públicas.

O artigo está organizado com mais quatro seções, assim sequenciadas: referencial teórico; problemas dos nem-nem no Brasil e evidências estatísticas; abordagem metodológica; discussão dos resultados; considerações finais.

\section{REFERENCIAL TEÓRICO}

\section{As Consequências da Condição Nem-Nem}

A literatura aborda diversas consequências negativas da permanência do indivíduo na inatividade durante parte da sua juventude, seja devido a períodos de desemprego ou de total exclusão do sistema educacional e do mercado de trabalho. É possível resumi-las em dois grupos: efeitos econômicos e efeitos pessoais e sociais. Sendo os primeiros relacionados às perspectivas de renda e emprego no curto, médio e longo prazo e os últimos à redução da qualidade de vida, aumento de atividades delituosas, entre outros.

Quanto aos efeitos econômicos, Gregg (2001) evidenciou que, no Reino Unido, os jovens que passaram um tempo desempregados experimentaram períodos adicionais fora do mercado de trabalho (seja desempregado ou inativo) entre os $28 \mathrm{e}$ 33 anos, sendo essa trajetória de dependência mais pronunciada para os homens. Resultados semelhantes foram obtidos por Maloney (2004) para a Nova Zelândia, ao identificarem que quanto mais longo o período de inatividade econômica na juventude, maior o "efeito redutor" sobre as perspectivas educacionais e laborais no futuro. OCDE (2005) reforça esses resultados argumentando que longos períodos de desemprego desgastam as habilidades dos jovens, reduz sua empregabilidade, causa uma perda permanente de capital humano e torna o desemprego persistente. Jovens com baixo capital humano e poucas habilidades estão particularmente 
expostos ao desemprego de longo prazo, a empregos de baixa qualidade e instáveis e talvez exclusão social. Entretanto, mais capital humano e altos níveis de educação não se traduzem automaticamente em melhora dos resultados no mercado de trabalho e em mais trabalho.

Ademais, Gregg e Tominey (2005) identificaram um efeito "redutor" sobre os salários dos jovens no Reino Unido, penalizando-os no médio e longo prazos. Constataram que são necessários 10 anos para esse efeito ser dissipado, desde que nenhum tempo de desemprego seja experimentado nesse período. Além disso, $8 \%$ desse efeito pode persistir até 20 anos após o período de desemprego, com impactos redutores sobre os salários de $13 \%-21 \%$ se o jovem passou por múltiplos períodos desempregado ou de $9 \%-11 \%$ se ele teve um único período nessa condição. Esse efeito, contudo, varia dependendo da idade em que o jovem ficou desempregado. Por exemplo, se o indivíduo permanece um ano desempregado antes dos 23 anos reduz cerca de $20 \%$ de sua renda nessa idade, com lenta recuperação ao longo dos próximos 20 anos. Ao atingir 30 e 42 anos de idade, a penalidade sobre sua renda se reduz para cerca de $15 \%$ e $10 \%$, respectivamente.

Similarmente, Mroz e Savage (2006) identificaram a penalidade sobre os salários, embora de menor magnitude, ao analisarem os efeitos de longo prazo do desemprego dos jovens sobre os resultados no mercado de trabalho dos Estados Unidos, e constatarem que o desemprego experimentado no passado continua a afetar adversamente os ganhos até 10 anos depois. Evidenciaram que indivíduos permanecendo 6 meses desempregados aos 22 anos receberiam, aos 30-31 anos, um salário $2 \%-3 \%$ menor do que outro que não esteve desempregado àquela idade. Mesmo que eles busquem se qualificar para voltar ao mercado de trabalho, não se recuperam completamente dos impactos adversos do desemprego.

Para Coles et al. (2010), o menor salário recebido por esses jovens está associado diretamente ao baixo nível educacional alcançado por eles, razão pela qual têm maior probabilidade de estarem em empregos menos qualificados, e assim com menores salários.

Signorelli et al. (2013) salientam ainda que, devido à mais baixa qualificação e experiência e sujeitos a contratos de trabalho mais flexíveis, os jovens são mais sensíveis ao ciclo de negócios do que os adultos, além de a elevada taxa de desemprego os desestimularem a procurar emprego. Em alguns casos eles postergam a busca por emprego e continuam no sistema educacional, mas em outros passam a integrar o grupo de jovens nem-nem.

Ademais, o baixo nível educacional resulta em diferenças salariais entre os jovens que tiveram sua transição para o mercado de trabalho marcada pela descontinuidade do ensino e/ou a intermitência no emprego com longos períodos de inatividade (nem-nem) e aqueles que não experimentaram essa condição, conforme Pacheco e Dye (2014). Esse diferencial pode ser explicado pelo fato de que quando esses indivíduos voltam ao mercado de trabalho, eles encontram empregos que exigem menor nível de habilidade que a contrapartida não nem-nem.

Para Samoilenko e Carter (2015), todavia, o efeito do desemprego sobre os ganhos futuros é ambíguo, pois alguns indivíduos são induzidos a aceitar empregos 
com baixos salários, enquanto outros terão um aumento nos ganhos de longo prazo se eles permanecerem algum tempo no desemprego procurando por um trabalho que se ajuste às suas habilidades e experiências. Ademais, indivíduos que ficaram como nem-nem na juventude mais do que 5 meses são mais suscetíveis de tornarem-se inativos e/ou receber benefícios sociais, o que pode ensejar em maior chance de permanecer dependentes de tais benefícios no futuro.

No que se refere aos efeitos pessoais e sociais, Goldsmith et al. (1996) verificaram que os jovens dos Estados Unidos que estiveram desempregados ou passaram um tempo fora da força de trabalho sofreram danos de longo prazo na autoestima e apresentaram sintomas de depressão, perda de identidade, ansiedade, agravados por dificuldades futuras no mercado de trabalho, corroborado posteriormente por Gerdtham e Johannesson (2003), Blanchflower (2011) e Eurofound (2012). Foram identificados ainda aumento da ocorrência de crimes entre os jovens inativos, particularmente entre os nem-nem, persistência no cometimento de delitos e do número de mortes precoces (Fergusson, et al., 2006; Coles et al., 2010; Wu e Wu, 2012). Outras análises também atestaram indícios de que a condição nem-nem está relacionada com a progressividade do uso de drogas ilícitas (Fergusson, et al., 2001; Blanchflower, 2011; Coles et al., 2010).

Málaga et al. (2014) destacam ainda que a intermitência no desemprego poderia prejudicar a autoestima dos jovens gerando desmotivação e desvinculação com o meio social. Por outro lado, características pessoais como a falta de habilidade de relacionar-se socialmente, o isolamento e a depressão também contribuem para não participação nas atividades laborais e na educação ou capacitação.

Marginalização e dependência química, problemas de saúde física e mental são identificados por Samoilenko e Carter (2015) como possíveis consequências aos jovens que passam um longo tempo na inatividade. Essas adversidades estendem-se também para sentimentos de solidão, impotência, ansiedade, depressão e exclusão com um aumento da associação a comportamentos de risco: maior uso de drogas, álcool e atividade criminal. Ademais, esses indivíduos são mais suscetíveis de tornarem-se pais mais jovens e enfrentarem problemas com habitação e falta de moradia. Com conclusões similares, Bãlan (2016) aponta que os mais importantes efeitos sociais dessa inatividade são o risco de pobreza, de autoexclusão e exclusão social, de desengajamento em nível individual expresso pela incapacidade de desempenhar um papel ativo na comunidade a que pertencem, e para o desenvolvimento da sociedade como um todo. Ainda como resultado desse status por um longo período podem surgir: isolamento, emprego em circunstâncias incertas e baixos salários, criminalidade, e falha em constituir família, uma vez que o status nem-nem afeta a coesão e a harmonia de uma família.

Quanto à participação política e social dos nem-nem, Bãlan (2016) constatou que eles são menos interessados em política do que os demais jovens, e são mais suscetíveis de perder a confiança nas instituições, dada a sensação de que as autoridades não são capazes de resolver as questões relacionadas ao seu status. A desconfiança de um elevado número de jovens que não estão incluídos no mercado de trabalho ou no sistema educacional/treinamento pode contribuir para a indetermi- 
nação da legitimidade dos líderes políticos, partidos políticos e instituições dentro da sociedade, visto que a participação ativa dos jovens no processo democrático é considerada um importante elemento da sustentabilidade da sociedade.

Em geral, essas evidências sugerem que os efeitos da condição nem-nem dos jovens são diversificados, complexos e persistentes, pois indicam que eles podem enfrentar várias desvantagens no longo prazo, não apenas no mercado de trabalho como na qualidade de vida, se comparados aos demais jovens.

\section{OS CUSTOS ATRELADOS AOS NEM-NEM}

Como relatado na literatura, o problema dos nem-nem se estende adversamente para a economia e a sociedade, e pode resultar em custos expressivos. Apesar disso, existem poucos trabalhos em âmbito internacional que tentaram estimar tais custos, e, nacionalmente, não se identificou nenhum com esse propósito.

No trabalho seminal de Godfrey et al. (2002), a estimação dos custos dos nem-nem do Reino Unido considerou tanto os custos individuais e familiares como para o restante da sociedade, ao analisarem seu impacto sobre as finanças públicas e sobre o custo de oportunidade dos recursos ${ }^{1}$. Foram examinados os custos correntes, de médio e de longo prazo, considerando a estimativa ao longo da vida desse grupo de jovens comparado com a suposição alternativa caso não fossem nem-nem. Para isso, seguiu-se uma metodologia em três estágios: (i) delinear os efeitos de ser nem-nem; (ii) fixar os custos desses efeitos para os indivíduos, suas famílias, bem como os custos de oportunidades e os cobertos pelas finanças públicas; (iii) multiplicar o número de pessoas experimentando uma consequência em particular pelo custo por pessoa. Os autores calcularam uma perda total de $0,62 \%$ do PIB em custos dos recursos e $0,72 \%$ do PIB em custos das finanças públicas. Dos custos estimados destacam-se como maiores aqueles associados ao desemprego, que totalizam $0,44 \%$ do PIB.

Esse exercício foi replicado por Coles et al. (2010), porém, com avanços metodológicos e com a inclusão de estudos de caso para captar os subgrupos de nem-nem de difícil identificação em pesquisas domiciliares. Esses estudos de caso foram usados para analisar os efeitos que as experiências e a dinâmica de exclusão social do trabalho exercem sobre subgrupos específicos. O total de custos correntes estimado corresponde a $0,12 \%$ do PIB do Reino Unido, para os custos de recursos, e $0,11 \%$ do PIB de custos para as finanças públicas. A maior parte desses custos é resultado do subemprego devido ao baixo nível educacional, ao desemprego e à inatividade econômica dos jovens, sugerindo que investimentos em estágios iniciais da carreira dos jovens podem fazer diferença entre uma vida adulta economicamente ativa e uma atribulada de períodos de inatividade econômica.

Com o objetivo de estimar a perda monetária corrente na economia europeia,

\footnotetext{
${ }^{1}$ Perdas de produtividade e bem-estar associadas ao uso subótimo dos fatores de produção.
} 
causada pelo desengajamento dos jovens nem-nem do mercado de trabalho e do sistema educacional, o estudo da Eurofound (2012) estimou os custos correntes com base no método proposto por Godfrey et al. (2002), porém, com aplicação da metodologia Propensity Score Matching (PSM) a fim de obter resultados mais confiáveis e robustos. As estimativas apontaram uma perda econômica de 1,2\% do PIB europeu em 2011, superando 2\% em alguns países (Grécia, Itália, Hungria, Irlanda e Polônia).

Pacheco e Dye (2014), por sua vez, propuseram conduzir uma análise de curto prazo através da estimação da perda de produtividade e os custos para as finanças públicas da Nova Zelândia associados aos jovens nem-nem. Esse estudo incluiu jovens desempregados, inativos e os que teriam baixos salários, caso entrassem na força de trabalho, devido ao baixo potencial educacional. Os resultados revelaram que os inativos geram os maiores custos comparados aos demais subgrupos analisados, tendo destaque os custos relativos à produtividade. Cabe destacar que, em termos per capita, o custo atribuído aos jovens de 20 a 24 anos é três vezes maior do que o de seus pares de 15 a 19 anos. Já os agregados são da ordem de US\$ 2,4 bilhões e correspondem a 1,3\% do PIB de 2012 da Nova Zelândia.

Embora exista considerável número de trabalhos que abordam os fatores de risco e as consequências da condição nem-nem, poucos, em nível internacional, quantificaram os custos econômicos, individuais e sociais a eles associados. Nesse sentido, este estudo contribui com a literatura ao propor a estimação dos custos econômicos dos nem-nem no Brasil.

\section{CENÁRIO DOS NEM-NEM NO BRASIL}

Dados da PNAD/IBGE revelam que a trajetória temporal dos nem-nem brasileiros de 15-24 anos é relativamente estável até 2007, oscilando em torno de 19\%, conforme se observa no Gráfico 1. Todavia, a partir de 2008, quando há uma queda acentuada na taxa de nem-nem, observa-se um crescimento contínuo nesse indicador até atingir $21,8 \%$ em 2015 , possivelmente reflexo da recessão econômica vivenciada no país com o crescimento expressivo do número de trabalhadores desempregados. Como resultado, nesse ano, do contingente de 33 milhões de jovens brasileiros, $22 \%$ deles (7,2 milhões) estavam fora da escola e do mercado de trabalho, e 13,8\% nem sequer procuravam emprego (inativos).

A distribuição dos nem-nem por estado sinaliza que esse problema persiste em todas as regiões do país, e mesmos os estados mais desenvolvidos têm uma proporção elevada dos seus jovens nessa condição. Dentre os estados com maiores taxas de nem-nem estão Pernambuco, Alagoas e Amapá, enquanto as menores encontram-se em Santa Catariana, Rio Grande do Sul e Mato Grosso do Sul. 
Gráfico 1: Evolução dos nem-nem por status no mercado de trabalho, Brasil, 2002-2015

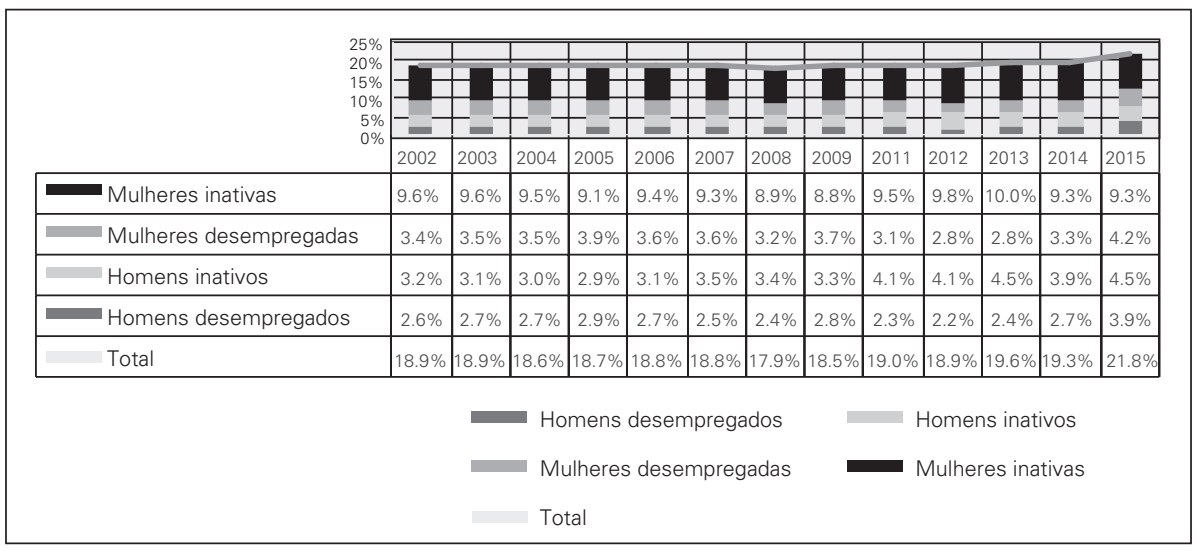

Fonte: Elaboração própria usando dados da PNAD/IBGE.

O Gráfico 2 mostra o nível educacional dos jovens por idade, gênero e condição nem-nem em 2015. Observa-se que independentemente do sexo e da idade considerados os nem-nem têm menos anos de estudo do que os não nem-nem, em média, 8,7 e 9,2, respectivamente. Ademais, sejam nem-nem ou não, as mulheres têm mais anos de estudo do que os homens. Nesse aspecto, Venturini e Torini (2014) apontam que apesar de as mulheres enfrentarem significativas dificuldades em se manterem na escola, sobretudo devido a maternidade e/ou a situação conjugal, elas têm maior aspiração de continuar os estudos, em níveis mais elevados do que os desejados pelos homens.

Gráfico 2: Anos de estudo dos jovens por idade, gênero e condição nem-nem - 2015

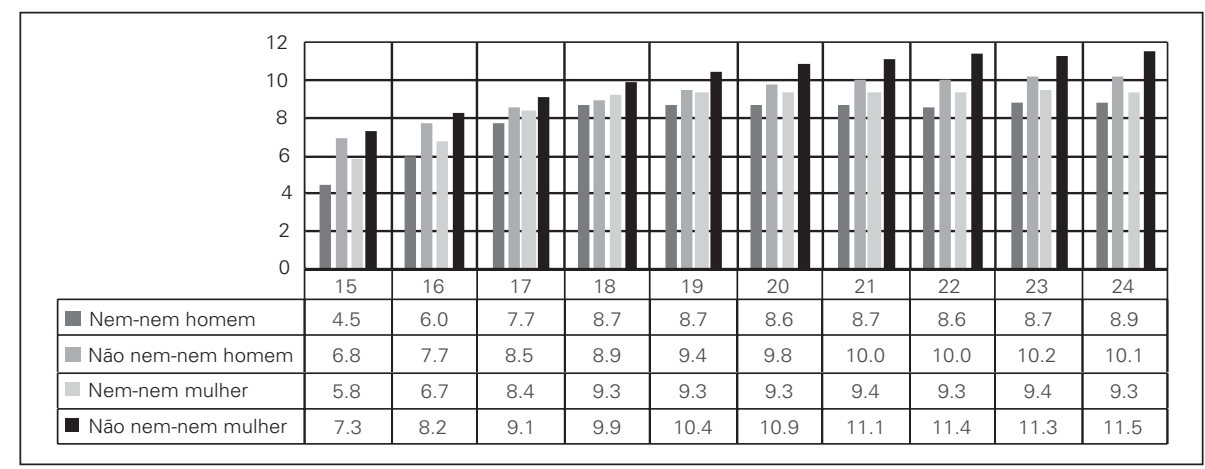

Fonte: Elaboração própria usando dados da PNAD/IBGE.

\section{ESTIMATIVAS DOS CUSTOS ECONÔMICOS DOS NEM-NEM}

Os estudos discutidos acima revelam que as consequências resultantes do desengajamento dos jovens do sistema educacional e do mercado de trabalho estão 
intrinsecamente associadas a elevados custos, tanto para a economia quanto para a sociedade. A computação desses custos é complexa, pois neles se inclui uma vasta rede de custos indiretos de difícil mensuração, além da escassez de dados disponíveis. Assim, para se proceder a uma análise de médio e longo prazo faz-se necessária a imposição de uma série de suposições para torná-la exequível. Como alternativa às limitações impostas por estimativas especulativas e fortes pressupostos, optou-se por restringir a estimação apenas aos custos correntes.

Não obstante essas limitações, os resultados advindos dessa aferição fornecem úteis subsídios para se prever a contribuição potencial para a sociedade e a economia, caso os jovens não se inserissem no status nem-nem, permitindo inferir um limiar inferior que pode auxiliar no desenho de políticas públicas que objetivem reduzir o número desses jovens. Para tanto, a abordagem metodológica adotada segue a proposta formulada pela Eurofound (2012), a qual é composta pelos seguintes estágios:

\begin{tabular}{|l|l|}
\hline Estágio 1 & $\bullet$ Definição e detalhamento dos custos a serem estimados. \\
\hline Estágio 2 & $\bullet$ Identificação metodológica dos jovens nem-nem. \\
\hline Estágio 3 & $\bullet$ Estimação dos custos dos recursos e para as finanças públicas por pessoa. \\
\hline Estágio 4 & $\bullet$ Com base nos estágios 2 e 3, procede-se ao cálculo dos custos totais. \\
\hline
\end{tabular}

\section{Estágio 1: Definição e implementação da estrutura de custos}

Do ponto de vista econômico, a perda decorrente da condição nem-nem se dá pela contribuição negativa para a formação do capital humano, com efeito direto sobre a redução da produtividade e, por conseguinte, para o crescimento econômico. O efeito direto sobre os próprios jovens seriam menores salários no futuro e piores oportunidades de trabalho, enquanto as firmas teriam seus lucros reduzidos pela redução da produtividade e da demanda. As famílias seriam afetadas pela menor disponibilidade de recursos para investir em saúde e educação, enquanto o Governo perderia arrecadação, seja via impostos diretos e/ou indiretos, deixando de investir em serviços públicos que beneficiariam a sociedade como um todo.

Nessa perspectiva, a estrutura de custos adotada neste estudo inclui o potencial de economia com o pagamento de benefícios (Bolsa Família e seguro-desemprego) a famílias cujos jovens nem-nem hipoteticamente não estivessem nessa condição, bem como a perda de arrecadação de contribuições, de impostos diretos e indiretos, devida à não participação dos jovens nem-nem no mercado de trabalho. Os custos relacionados à não participação dos nem-nem no mercado de trabalho capturam a diferença entre o produto potencial e o real, e, assim, a perda de produtividade para a economia. Eles são definidos como a renda potencial que o nem-nem teria se estivesse engajado no mercado de trabalho. 
Seguindo Godfrey et al. (2002) esses custos serão determinados como o excesso do custo dos nem-nem numa situação hipotética comparado com o que eles poderiam ter experimentado em situação contrária. Sua implementação empírica neste trabalho será avaliada através dos microdados da Pesquisa Nacional de Amostra por Domicílio (PNAD) de 2015.

\section{Estágio 2: Identificação da população nem-nem}

Uma vez definida e implementada a estrutura de custos, estabeleceu-se o critério para delimitar a população objeto de estudo. Seguindo a definição da Organização Internacional do Trabalho (OIT $)^{2}$ foram considerados como nem-nem os jovens com idade $15-24^{3}$ que não estudam e não trabalham, incluídos nessa última categoria os desempregados e aqueles não contabilizados na População Economicamente Ativa (PEA) e os inativos.

Conforme Eurofound (2012), o grupo dos nem-nem é composto por uma população bastante heterogênea com vários subgrupos dispostos em características próprias e níveis diferenciados de vulnerabilidade. Em vista disso e das limitações dos dados, este estudo segue Dye e Pacheco (2014) ao associar os custos nos subgrupos de desempregados e inativos. Optou-se ainda em dividir esses subgrupos por gênero devido às diferenças dos fatores explicativos que atestam a condição nem-nem entre homens e mulheres ${ }^{4}$, além de suas distribuições na amostra em estudo, conforme a Figura 1.

Nesse sentido, o Relatório de Indicadores Sociais de 2016 do IBGE aponta que a grande diferença na proporção de homens e mulheres na condição nem-nem se deve sobretudo a questões culturais e/ou práticas discriminatórias de gênero, em que as mulheres são excluídas do mercado de trabalho e direcionadas a ocupação de afazeres domésticos. Conforme detalha a Figura 1, as mulheres perfazem quase o dobro dos homens no grupo dos nem-nem, e a maioria dessas jovens nem sequer procuram emprego. Para os homens, apesar dos inativos também serem a maior parte do grupo, a diferença entre desempregados e inativos é menos acentuada.

\section{Estágio 3: Cálculo dos custos por pessoa usando o PSM}

O ônus do fenômeno nem-nem é definido pelos custos adicionais que o jovem tem que incorrer em virtude dessa condição, quando comparado a um jovem não nem-nem com características equivalentes. Assim, é possível obter uma aproximação do contrafactual da renda auferida por esses indivíduos observando aquela obtida por seus pares que se encontram trabalhando.

\footnotetext{
${ }^{2}$ A OIT usa o termo NEET (Neither in Employment nor in Education or Training), entretanto, os dados brasileiros não permitem levantar informações sobre o treinamento e outros cursos de capacitação.

${ }^{3}$ Conforme definida pela Organização das Nações Unidas (ONU).

${ }^{4}$ Ver Silva e Kassouf (2002) e Monteiro (2013).
} 


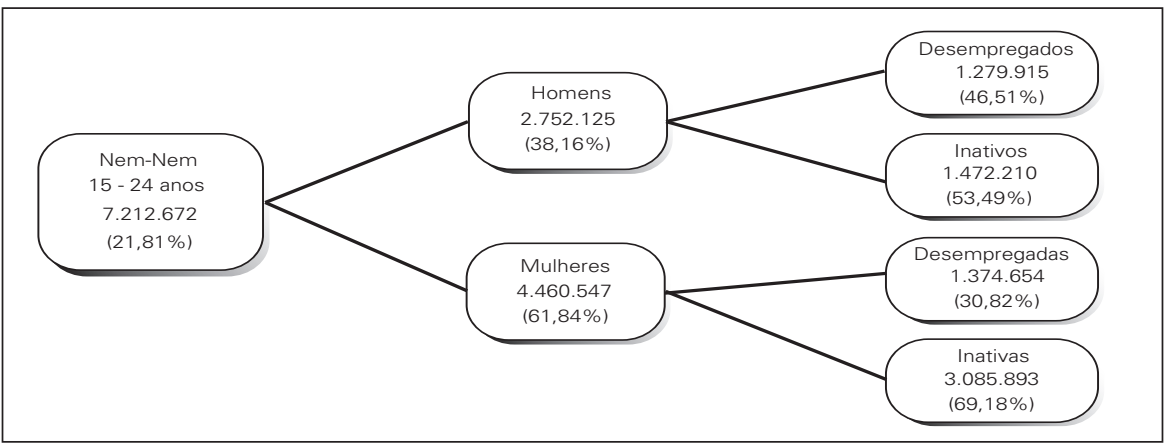

Fonte: Elaboração própria com base nos dados da PNAD/IBGE 2016.

Uma forma simples de chegar a esse valor seria tomar a média de rendimentos obtida no mercado de trabalho pelos jovens não nem-nem na mesma faixa etária. Contudo, esse procedimento não considera a heterogeneidade de características desses jovens, o que provavelmente resultaria em uma estimação fortemente viesada.

Para minimizar esse problema, bem como reduzir os vieses de características não observadas, optou-se pela aplicação do método Propensity Score Matching (PSM) proposto por Rosenbaum e Rubin (1983), assim como seguido por Eurofound (2012). Esse método permite considerar as diferentes características dos jovens combinando os indivíduos de acordo com sua probabilidade condicional de serem nem-nem, tornando o grupo de comparação mais plausível.

Para tanto, os autores propõem que a seleção do grupo de comparação pode ser realizada com base em uma função que resuma toda a informação contida nas características observáveis, as quais são assumidas como determinantes para a participação do indivíduo nesse grupo e para sua renda potencial, hipótese conhecida como Seleção nos Observáveis ou Ignorabilidade. Dessa forma, uma limitação do PSM decorre da existência de diferenças não observadas entre os nem-nem e o grupo de controle que poderiam afetar a probabilidade de ocorrer nem-nem. A estimação do escore de propensão é feita a partir de um modelo de escolha discreta binária sob a hipótese probit, cuja especificação geral é dada por:

$$
P(Y=1 \mid X)=\Phi(\mathrm{X} \beta)+\varepsilon
$$

Onde Y é a variável dependente binária que indica se o jovem é ou não nem-nem, $\mathrm{X}$ é o conjunto das características observadas que explicam a probabilidade de um jovem vir a ser nem-nem, o qual é composto pelas variáveis: idade, anos de estudo, sexo, status de migração, cor, mora com cônjuge ou companheiro, renda domiciliar per capita, idade, cor e educação do chefe da família, mora com mãe, razão de aposentados e pensionistas no domicílio, faz os afazeres domésticos, número de crianças até dez anos de idade que residem no domićlio, outro nem-nem no domicílio, local da residência, região em que mora. $\Phi$ é a função de probabilidade acumulada da distribuição normal padrão. 
O valor do escore de propensão predito a partir desse modelo reporta a probabilidade condicional de cada indivíduo ser nem-nem dadas suas características observáveis. Com base nesse valor, utiliza-se algum critério de escolha que selecione para cada jovem nem-nem um ou mais indivíduos fora dessa condição que o represente em termos dessa probabilidade. Para tanto, foi utilizado o método radius matching, um algoritmo de pareamento que escolhe para determinado indivíduo todos os jovens não nem-nem cujo escore de propensão está distante até cinco pontos percentuais. Ou seja, cada nem-nem é comparado a um grupo de controle (não nem-nem) que pertence a uma vizinhança predefinida com base no escore de propensão calculado. Os resultados da estimação do Modelo Probit estão na Tabela 8 e os gráficos de ajustamento do pareamento encontram-se disponíveis nos Gráficos 3(a) e 3(b) no final deste artigo.

A partir do procedimento descrito, define-se o grupo de controle e, através da observação do rendimento médio desses indivíduos, obtém-se uma estimativa da renda que um jovem nem-nem auferiria se estivesse participando do mercado de trabalho. Assumindo que jovens nessa condição permanecem, em média, mais tempo fora do mercado de trabalho, foram calculados os custos por pessoa segundo cada subgrupo de nem-nem (desempregados e inativos).

No caso dos nem-nem desempregados, assumiu-se que o tempo de desemprego entre eles é 50\% maior que a média, seguindo Godfrey et al. (2002) e Dye e Pacheco (2014). Ademais, o tempo de desemprego foi definido a partir da duração média de procura por emprego do brasileiro disponibilizado pela Pesquisa de Emprego e Desemprego (PED) de 2015 do Departamento Intersindical de Estatística e Estudos Sociais e Econômicos (DIEESE).

Conforme disposto na Tabela 1, os jovens passam, em média, 8 meses procurando emprego, distribuídos em 7,5 e 8,5 meses para homens e mulheres, respectivamente. Quanto a rendimentos, os nem-nem homens deixam de receber mensalmente, em média, $\mathrm{R} \$ 812,07$, enquanto as mulheres $\mathrm{R} \$ 800,83^{5}$. Esses valores sinalizam características comuns de que tais jovens tendem a ocupar postos com menor estabilidade no mercado de trabalho e, consequentemente, menores salários. Além do mais, o maior tempo na condição de inatividade das jovens faz com elas absorvam maiores perdas de rendimento do que os homens. Em média, deixam de receber $\mathrm{R} \$ 3.826,17$, equivalentemente a quase cinco salários mínimos por ano, devido ao tempo adicional no desemprego, característica do status nem-nem.

$\mathrm{O}$ valor da renda bruta não ganha dos nem-nem inativos foi obtido com base na renda média dos jovens do grupo de controle (não nem-nem), selecionados pelo PSM conforme procedimento descrito anteriormente. Já o tempo da inatividade baseou-se no estudo de Menezes-Filho et al. (2013), segundo o qual as mulheres têm maior taxa de inatividade do que os homens, cujos tempos médios nessa condição são de 4,5 e 3 meses, respectivamente. Na Tabela 2 estão explicitados os custos por pessoa decorrentes das hipóteses assumidas.

\footnotetext{
${ }^{5}$ O salário mínimo em 2015 era de R\$ 788,00.
} 
Tabela 1: Tempo de desemprego e rendimentos

não ganhos do Nem-Nem por gênero, 2015

\begin{tabular}{c|c|c|c|c}
\hline Gênero & $\begin{array}{c}\text { Tempo } \\
\text { desempregado } \\
\text { (meses) }\end{array}$ & $\begin{array}{c}\text { Tempo adicional } \\
\text { desempregado } \\
\text { (meses) }\end{array}$ & $\begin{array}{c}\text { Ganhos médios } \\
\text { mensais (R\$) }\end{array}$ & $\begin{array}{c}\text { Rendimento anual } \\
\text { não ganho no ano* } \\
\text { (R\$) }\end{array}$ \\
\hline Homens & 7,5 & $\mathrm{~A}$ & $\mathrm{~A} \times \mathrm{B}$ \\
Mulheres & 8,5 & 3,7 & 812,07 & $3.338,52$ \\
\hline
\end{tabular}

Fonte: Elaboração própria com base nos dados do DIEESE.

Nota: * Considera o proporcional de gratificação natalina e férias.

Tabela 2: Tempo de inatividade e rendimentos não ganhos do Nem-Nem por gênero, 2015

\begin{tabular}{c|c|c|c}
\hline Gênero & $\begin{array}{c}\text { Tempo de } \\
\text { inatividade (meses) } \\
\text { A }\end{array}$ & $\begin{array}{c}\text { Ganhos médios } \\
\text { mensais* (R\$) } \\
\text { B }\end{array}$ & $\begin{array}{c}\text { Rendimento anual } \\
\text { não ganho no ano* } \\
\text { (R\$) } \\
\text { A } \times \text { B }\end{array}$ \\
\hline Homens & 3 & 789,01 & $2.630,04$ \\
Mulheres & 4,5 & 613,42 & $3.067,10$ \\
\hline
\end{tabular}

Fonte: Elaboração própria com base nos resultados do PSM.

(*) Considera o proporcional de gratificação natalina e férias.

De forma semelhante ao que ocorre no subgrupo dos nem-nem desempregados, as mulheres permanecem mais tempo na inatividade e, em média, ganham menos que os homens. No ano, o total não ganho por cada jovem inativa foi, em média, $\mathrm{R} \$ 3.067,10$, ou seja, $16,62 \%$ a mais que a perda de rendimento do jovem inativo. Nota-se ainda que o rendimento médio não ganho pelos nem-nem inativos é menor do que aquele que os nem-nem desempregados deixaram de receber.

Esses rendimentos não efetivados se refletem na perda de arrecadação tributária por parte do governo e aumento dos gastos públicos no curto, médio e longo prazo, uma vez que essa restrição de renda faz com que os jovens nem-nem não só reduzam o consumo de bens e serviços como também deixem de contribuir para a previdência social. A ocorrência disso faz com que eles se tornem mais suscetíveis de necessitar de políticas públicas assistenciais de curto e longo prazos.

A perda de receita tributária foi mensurada a partir das estimativas da distribuição da carga tributária do brasileiro obtidas de Siqueira et al. (2012), as quais consideram a incidência tributária para diferentes níveis de renda familiar per capita, referente a tributos diretos (INSS e IR) e indiretos (ICMS, IPI e outros), conforme Tabela 3. 
Tabela 3: Distribuição da Carga Tributária por Decil de Renda

\begin{tabular}{c|c|c|c|c|c|c|c|c}
\hline \multirow{2}{*}{$\begin{array}{c}\text { Decil de renda } \\
\text { familiar per } \\
\text { capita }\end{array}$} & \multicolumn{7}{|c|}{ Direta } & \multicolumn{5}{c|}{ Indireta } & \multirow{2}{*}{ Total } \\
\cline { 2 - 7 } & INSS & IR & Total & ICMS & IPI & Outros & Total & \\
\cline { 2 - 7 } 1 & 1.0 & 0.0 & 1.0 & 9.1 & 1.2 & 5.1 & 15.4 & 16.4 \\
2 & 1.6 & 0.0 & 1.6 & 8.6 & 1.1 & 4.9 & 14.7 & 16.3 \\
3 & 2.7 & 0.0 & 2.7 & 8.6 & 1.1 & 4.8 & 14.5 & 17.2 \\
4 & 3.1 & 0.0 & 3.1 & 8.5 & 1.1 & 4.8 & 14.4 & 17.5 \\
5 & 3.7 & 0.0 & 3.7 & 8.1 & 1.0 & 4.6 & 13.7 & 17.4 \\
6 & 2.8 & 0.0 & 2.8 & 8.0 & 1.0 & 4.6 & 13.6 & 16.4 \\
7 & 4.3 & 0.0 & 4.3 & 7.7 & 1.1 & 4.5 & 13.3 & 17.6 \\
8 & 4.4 & 0.4 & 4.8 & 7.4 & 1.1 & 4.6 & 13.1 & 17.9 \\
9 & 4.4 & 1.2 & 5.6 & 7.1 & 1.1 & 4.5 & 12.7 & 18.3 \\
10 & 4.2 & 6.1 & 10.3 & 5.8 & 1.0 & 4.1 & 10.9 & 21.2 \\
\hline
\end{tabular}

Fonte: Adaptado de Siqueira et al. (2012).

Essa renda familiar tenderia a elevar-se com a inclusão da renda dos nem-nem, caso esses estivessem trabalhando, o que, por sua vez, elevaria o nível de tributação devida. Assim, o total de tributos não recolhidos pelo nem-nem foi obtido comparando o valor que ele pagaria, dada a sua renda familiar per capita (efetiva) com o valor a ser pago caso estivesse auferindo a renda calculada a partir do contrafactual. As estimativas da receita tributária potencial, por indivíduo, estão dispostas na Tabela 4.

Tabela 4: Receita Tributária Não Arrecadada por Nem-Nem Desempregado e Inativo, 2015

\begin{tabular}{c|c|c|c|c}
\hline \multirow{2}{*}{$\begin{array}{c}\text { Fonte de receita } \\
\text { tributária }\end{array}$} & \multicolumn{2}{|c|}{ Nem-nem desempregados } & \multicolumn{2}{c}{ Nem-nem inativos } \\
\cline { 2 - 5 } & Homem & Mulher & Homem & Mulher \\
\hline Tributos diretos & $\mathrm{R} \$ 310,68$ & $\mathrm{R} \$ 287,73$ & $\mathrm{R} \$ 320,31$ & $\mathrm{R} \$ 200,73$ \\
& $\mathrm{R} \$ 1.362,16$ & $\mathrm{R} \$ 1.353,33$ & $\mathrm{R} \$ 1.338,63$ & $\mathrm{R} \$ 1.048,02$ \\
\hline $\begin{array}{c}\text { Tributos indiretos } \\
\begin{array}{c}\text { Perda de receita } \\
\text { tributária }\end{array}\end{array}$ & $\mathrm{R} \$ 1.672,84$ & $\mathrm{R} \$ 1.641,07$ & $\mathrm{R} \$ 1.658,95$ & $\mathrm{R} \$ 1.248,75$ \\
\hline
\end{tabular}

Fonte: Elaboração própria com base nos resultados do PSM.

Nota-se que embora o potencial de receita tributária seja semelhante nos dois subgrupos analisados, ele é maior no subgrupo dos nem-nem desempregados. Verifica-se ainda que os homens contribuiriam mais na arrecadação dos tributos, sendo essa diferença mais expressiva no subgrupo dos nem-nem inativos. Quanto à 
fonte de arrecadação, é substancial os impostos indiretos no potencial contributivo, representando, em média, $82 \%$ do total da perda de receita tributária estimada.

No que se refere à economia dos gastos públicos oriundos da reinserção dos jovens no sistema educacional e/ou no mercado de trabalho este estudo analisou dois benefícios que seriam impactados com essa medida: Programa Bolsa Família (PBF) e Seguro Desemprego (SD).

O PBF é um programa de transferência direta de renda às famílias em situação de pobreza e extrema pobreza que busca garantir-lhes o direito à alimentação e o acesso à saúde e à educação, de modo a superar a situação de vulnerabilidade social. Segundo dados do Ministério de Desenvolvimento Social (MDS) de 2015, cerca de 13,9 milhões de famílias foram beneficiadas com R \$ 27 bilhões do Governo Federal.

O principal critério de elegibilidade desse programa é a renda familiar per capita. Com base nisso, se jovens nem-nem fossem reengajados no mercado de trabalho haveria um aumento na renda familiar e uma redução do número de famílias elegíveis ao PBF, assim como do montante de recursos a serem transferidos para o Programa.

Os custos com o pagamento do PBF foram estimados considerando quatro tipos de benefícios, cujas designações, condicionalidades e respectivos valores imputados estão dispostos no Quadro 1. No cômputo desses custos utilizou-se a renda familiar obtida pelo PSM baseada no potencial ganho dos jovens caso não estivessem na condição nem-nem.

Quadro 1: Programa Bolsa Família - Tipos e Valores dos Benefícios - 2015

\begin{tabular}{|c|c|c|}
\hline Tipo de Benefício & Condicionalidade & Valor Mensal \\
\hline Básico & $\begin{array}{l}\text { Famílias em situação de extrema pobreza } \\
\text { (renda mensal per capita até } \mathrm{R} \$ 85,00 \text { ). }\end{array}$ & $\mathrm{R} \$ 85,00 /$ pessoa. \\
\hline Variável & $\begin{array}{l}\text { Famílias pobres e extremamente } \\
\text { pobres que tenham em sua } \\
\text { composição gestantes, nutrizes e } \\
\text { crianças e adolescentes de } 0 \text { a } 16 \text { anos } \\
\text { incompletos*. }\end{array}$ & $\begin{array}{l}\mathrm{R} \$ 39,00 / \text { família, podendo acu- } \\
\text { mular até } 5 \text { benefícios } \\
\text { (R\$195,00). Para famílias com } \\
\text { crianças de } 0 \text { a } 6 \text { meses o } \\
\text { benefício pode ser pago em } \\
\text { até } 6 \text { parcelas mensais } \\
\text { consecutivas. }\end{array}$ \\
\hline Variável jovem & $\begin{array}{l}\text { Famílias pobres e extremamente } \\
\text { pobres que tenham em sua composição } \\
\text { adolescentes entre } 16 \text { e } 17 \text { anos. }\end{array}$ & $\begin{array}{l}\mathrm{R} \$ 46,00 / \text { família, podendo } \\
\text { acumular até } 2 \text { benefícios }(\mathrm{R} \$ \\
92,00) \text {. }\end{array}$ \\
\hline $\begin{array}{c}\text { Superação da } \\
\text { extrema pobreza }\end{array}$ & $\begin{array}{l}\text { Famílias em situação de extrema } \\
\text { pobreza, podendo acumular o benefício } \\
\text { Básico, o Variável e o Variável Jovem } \\
\text { até } \mathrm{R} \$ 372,00 / \text { mês. Podem também } \\
\text { acumular } 1 \text { (um) benefício para } \\
\text { superação da extrema pobreza. }\end{array}$ & $\begin{array}{l}\text { Varia em razão do cálculo } \\
\text { realizado a partir da renda } \\
\text { por pessoa da família e do } \\
\text { benefício já recebido no } \\
\text { Programa. }\end{array}$ \\
\hline
\end{tabular}

Nota: * Para o cálculo dos custos com o PBF o benefício variável das gestantes foi desconsiderado. 
Quanto ao cálculo do SD, foram consideradas as mudanças das regras para obtenção desse benefício advindas da Lei $\mathrm{N}^{\circ}$ 13.134/2015 em vigor desde junho/2015, as quais afetaram basicamente os indivíduos que solicitaram o benefício pela primeira e segunda vez. A partir da terceira solicitação as regras permaneceram as mesmas da lei anteriormente vigente (Lei $\mathrm{N}^{\circ}$ 7.998/1990), conforme explicitadas na Tabela 5.

Tabela 5: Número de Parcelas do Seguro-Desemprego

\begin{tabular}{c|c|c}
\hline Solicitação & $N^{\circ}$ parcelas & $N^{\circ}$ meses que recebeu salário nos últimos 36 meses \\
\hline \multirow{2}{*}{$1^{\text {a }}$} & 4 & {$[12 ; 23)$} \\
& 5 & 24 \\
\cline { 2 - 3 } & 3 & {$[9 ; 11]$} \\
$2^{\text {a }}$ & 4 & {$[12 ; 23]$} \\
& 5 & 24 \\
\hline \multirow{3}{*}{ A partir da $3^{a}$} & 3 & {$[6 ; 11]$} \\
& 5 & {$[12 ; 23]$} \\
& 4 & 24 \\
\hline
\end{tabular}

Fonte: Elaboração própria com base na Lei 13.134/2015.

Para estimar o valor do SD, foi utilizado o método de cálculo do benefício definido pelo MTE, disposto na Tabela 6, e pressuposto que os nem-nem recebem mais benefícios deste seguro do que os demais jovens, conforme já caracterizada a relação deles com o mercado de trabalho. Adotando uma prerrogativa bastante conservadora, assumiu-se também que todos os jovens que receberam o SD haviam solicitado o benefício pela primeira vez. Visto que a renda média estimada para a amostra em estudo foi menor do que R \$ 1.222,77, o valor do benefício foi obtido por meio da multiplicação do salário médio por 0,8 .

Tabela 6: Cálculo do Benefício do Seguro-Desemprego

\begin{tabular}{c|c}
\hline Faixas de Salário Médio* & Valor da Parcela \\
\hline Até $\mathrm{R} \$ 1.222,77$ & Multiplica-se o salário médio 0,8 (80\%). \\
De $\mathrm{R} \$ 1.222,78$ até $\mathrm{R} \$ 2.038,15$ & $\begin{array}{r}\text { O que exceder a } \mathrm{R} \$ 1.222,77 \text { multiplica-se } \\
\text { por } 0,5(50 \%) \text { e soma-se a } \mathrm{R} \$ 978,22 .\end{array}$ \\
Acima de $\mathrm{R} \$ 2.038,15$ & O valor da parcela será de $\mathrm{R} \$ 1.385,91$ invariavelmente. \\
\hline
\end{tabular}

Fonte: MTE. * O valor do Salário Médio dos últimos três meses anteriores à dispensa.

Dadas essas hipóteses, foram calculados os gastos assistenciais com o pagamento do PBF e do SD, cujos resultados estão na Tabela 7. Os valores explicitam o potencial de redução de gastos públicos correspondentes aos benefícios, em nível individual, que adviriam da inserção de cada jovem nem-nem no mercado de trabalho, esteja ele desempregado ou inativo. 
Tabela 7: Gastos Assistenciais por Nem-Nem, 2015

\begin{tabular}{|c|c|c|c|c|}
\hline \multirow{2}{*}{ Gasto assistencial } & \multicolumn{2}{|c|}{ Nem-nem desempregados } & \multicolumn{2}{|c|}{ Nem-nem inativos } \\
\hline & Homem & Mulher & Homem & Mulher \\
\hline PBF & $\mathrm{R} \$ 254,15$ & $\mathrm{R} \$ 250,73$ & $\mathrm{R} \$ 375,88$ & $\mathrm{R} \$ 405,46$ \\
\hline SD & $\mathrm{R} \$ 286,18$ & $\mathrm{R} \$ 127,38$ & $\mathrm{R} \$ 42,33$ & $\mathrm{R} \$ 46,74$ \\
\hline
\end{tabular}

Fonte: Elaboração própria.

Nota-se que a maior contenção dos gastos está no pagamento do PBF, mais especificamente no subgrupo dos inativos, além de destacar a reincidência de maiores valores no grupo das mulheres em inatividade que, em média, representaria um montante de $\mathrm{R} \$ 405,46,8 \%$ superior ao correspondente dos homens. A contenção oriunda do SD é notoriamente maior no subgrupo de nem-nem desempregados e do sexo masculino.

Tabela 8: Resultados do Modelo Probit

\begin{tabular}{|c|c|c|c|c|}
\hline \multirow{2}{*}{$\begin{array}{c}\text { Nem-nem } \\
\text { Variáveis }\end{array}$} & \multicolumn{2}{|c|}{ Desempregados } & \multicolumn{2}{|c|}{ Inativos } \\
\hline & Coeficiente & Erro-Padrão & Coeficiente & Erro-Padrão \\
\hline Idade & $0,038^{*}$ & 0,008 & $-0,023^{*}$ & 0,006 \\
\hline Anos_est & 0,005 & 0,007 & $-0,093^{*}$ & 0,005 \\
\hline Homem & $-0,058$ & 0,037 & $-0,553^{*}$ & 0,033 \\
\hline Migrante & $-0,017$ & 0,041 & 0,002 & 0,036 \\
\hline Mora_mãe & 0,115 & 0,155 & $-0,214 * * *$ & 0,119 \\
\hline NN_dom & $0,162 *$ & 0,020 & $0,197^{*}$ & 0,018 \\
\hline Renda_dpc & $-0,001 *$ & 0,000 & $-0,001^{*}$ & 0,000 \\
\hline Razaoapo_pen & $-0,122^{*}$ & 0,153 & $-0,021$ & 0,131 \\
\hline Urbana & $0,502^{*}$ & 0,049 & $0,177^{*}$ & 0,038 \\
\hline Nordeste & $0,200 *$ & 0,053 & 0,048 & 0,044 \\
\hline Sul & $-0,112 * * *$ & 0,066 & $-0,391 *$ & 0,055 \\
\hline Sudeste & $0,168^{*}$ & 0,054 & $-0,202^{*}$ & 0,046 \\
\hline Centro-Oeste & 0,028 & 0,071 & $-0,251^{*}$ & 0,062 \\
\hline Companheiro(a) & $-0,147^{*}$ & 0,079 & $-0,002$ & 0,068 \\
\hline Criança10 & 0,000 & 0,022 & $-0,002$ & 0,018 \\
\hline Branca & 0,004 & 0,036 & $0,108^{*}$ & 0,033 \\
\hline Afaz_dom & $0,489 *$ & 0,037 & $0,133^{*}$ & 0,033 \\
\hline Chefe_homem & 0,096 & 0,100 & 0,008 & 0,086 \\
\hline Chefe_idade & 0,000 & 0,002 & $-0,002$ & 0,002 \\
\hline Chefe_fund & 0,047 & 0,040 & 0,028 & 0,038 \\
\hline Chefe_med & 0,064 & 0,126 & $0,318^{*}$ & 0,107 \\
\hline Chefe_sup & $0,238^{*}$ & 0,072 & $0,411^{*}$ & 0,059 \\
\hline Constante & $-2,712^{*}$ & 0,234 & $0,873^{*}$ & 0,183 \\
\hline Chi2 & \multicolumn{2}{|c|}{$818,66^{*}$} & \multicolumn{2}{|c|}{$1122,99 *$} \\
\hline No observações & \multicolumn{2}{|c|}{9812} & \multicolumn{2}{|c|}{10520} \\
\hline
\end{tabular}

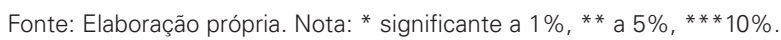




\section{Estágio 4: Cálculo dos custos totais}

A estimação dos custos totais tem por base as informações obtidas nos estágios anteriores, quais sejam, o custo por pessoa e o número de jovens na condição nem-nem, cujos resultados estão explicitados nas Tabelas 9 e 10.

Tabela 9: Custo Individual dos Jovens Nem-Nem

\begin{tabular}{l|cc|cc}
\hline \multirow{2}{*}{ Descrição do Custo } & \multicolumn{2}{|c|}{ Inativos } & \multicolumn{2}{c}{ Desempregados } \\
& Homem & Mulher & Homem & Mulher \\
\hline Perda de RT & $1.658,95$ & $1.248,75$ & $1.672,84$ & $1.641,07$ \\
Pagamento PBF & 375,88 & 405,46 & 254,15 & 250,73 \\
Pagamento SD & 42,33 & 46,74 & 286,18 & 127,38 \\
Renda não-ganha & $2.630,04$ & $3.067,10$ & $3.338,52$ & $3.826,17$ \\
\hline Custo por indivíduo & $4.707,20$ & $4.768,05$ & $5.551,69$ & $5.845,35$ \\
\hline
\end{tabular}

Fonte: Elaboração própria.

Tabela 10: Custo Total dos Jovens Nem-Nem por Gênero e Classificação de Atividade

\begin{tabular}{l|cc|cc}
\hline \multirow{2}{*}{$\begin{array}{l}\text { Descrição } \\
\text { do Custo }\end{array}$} & \multicolumn{2}{|c|}{ Inativos } & \multicolumn{2}{c}{ Desempregados } \\
& Homem & Mulher & Homem & Mulher \\
\hline RT total & 2.442 .317 .474 & 3.853 .495 .541 & 2.141 .094 .217 & 2.225 .897 .285 \\
PBF total & 553.372 .116 & 1.251 .206 .052 & 325.291 .216 & 344.670 .352 \\
SD total & 62.321 .747 & 144.235 .870 & 366.284 .116 & 175.101 .720 \\
$\begin{array}{l}\text { Produtividade } \\
\text { total }\end{array}$ & 3.871 .974 .133 & 9.464 .733 .163 & 4.273 .696 .992 & 5.259 .658 .179 \\
\hline$N^{\circ}$ de nem- & 1.472 .210 & 3.085 .893 & 1.279 .915 & 1.374 .654 \\
-nem & 6.929 .985 .469 & 14.713 .670 .627 & 7.105 .696 .992 & 8.035 .328 .076 \\
\hline Custos totais & 0,12 & 0,25 & 0,12 & 0,13 \\
\hline \multicolumn{1}{c}{$\%$ PIB } & & & & \\
\hline
\end{tabular}

Fonte: Elaboração própria.

É importante ressalvar que os custos estimados podem se sobrepor parcialmente, razão pela qual eles são calculados separadamente, e somente agregados para propósitos ilustrativos. Os resultados expostos na Tabela 11 mostram que os custos econômicos decorrentes do fenômeno nem-nem correspondiam a $0,61 \%$ do PIB em 2015. Ou seja, pelo menos R $\$ 36$ bilhões poderiam ter sido alocados em políticas públicas que se reverteriam em aumento de bem-estar da sociedade brasileira em diversas formas de distribuição. Para ilustrar, essa magnitude de recursos permitiria dobrar o número de famílias beneficiadas com o PBF. Enfatiza-se, assim, que apesar da adoção de hipóteses bastante conservadoras e cautelosas na estimativa desses custos, eles são bastante elevados. 
Tabela 11: Custos Totais dos Jovens Nem-Nem

\begin{tabular}{lr}
\hline Descrição do Custo & Total \\
\hline RT total & 10.692 .804 .517 \\
PBF total & 2.474 .539 .736 \\
SD total & 747.943 .453 \\
Produtividade total & 22.869 .393 .458 \\
\hline $\mathrm{N}^{0}$ de nem-nem & 7.212 .672 \\
Custos totais & 36.784 .681 .164 \\
\% PIB & 0,61 \\
\hline
\end{tabular}

Fonte: Elaboração própria.

Do total dos custos estimados, verifica-se que os mais expressivos são relacionados à perda de produtividade da economia, seguidos pela perda de receitas tributárias (RT) e gastos com o PBF e SD, respectivamente.

Devido à elevada proporção de jovens economicamente inativos, vis-à-vis aos jovens desempregados, os custos respectivos estimados de R \$21,6 bilhões e R \$ 15,1 bilhões são deveras significativos, implicando com isso que, além do problema de oferta do mercado de trabalho, acirram-se a desmotivação e desencorajamento de milhões de jovens para atividades produtivas. Assim, mesmo que políticas públicas sejam criadas no intuito de inserir os jovens no mercado de trabalho via capacitação ou treinamentos, não se descarta a possibilidade de elas atingirem apenas parte dos jovens nem-nem.

Ressalta-se, todavia, que essas estimativas são bastantes sensíveis ao contexto econômico de 2015, ano em que ocorria uma grave recessão no país. Como consequência, milhares de postos de trabalho foram fechados, acarretando em desemprego de milhões de brasileiros. Devido à pouca experiência no mercado de trabalho e ao próprio período de transição em que vivem, os trabalhadores mais jovens são mais suscetíveis de ficarem desempregados em situações de crise, uma vez que grande parcela se dedica a ocupações temporárias, altamente instáveis no cenário econômico desfavorável.

Considerando os custos correntes por gênero, observa-se que eles são mais elevados para as jovens nem-nem e destacadamente as inativas. Considerando os subgrupos analisados, a diferença dos custos por gênero é mais pronunciada no grupo dos inativos, em que o custo das jovens nem-nem é mais do que o dobro do verificado para o correspondente do sexo masculino. Esses resultados sugerem, então, a necessidade de políticas públicas mais direcionadas a esse subgrupo de jovens que segundo resultados da literatura têm-se apresentado como um grupo de alto risco de vulnerabilidade social e econômica (Corseuil et al., 2001; Aguila et al., 2013; Menezes-Filho et al., 2013; Monteiro, 2013). 


\section{CONCLUSÃO}

Em 2015, cerca de 7,2 milhões de jovens de 15 a 24 anos estavam na condição nem-nem. Embora para alguns seja um status temporário resultante da transição escola-trabalho, para outros pode ter efeitos duradouros, com repercussão sobre os salários e a empregabilidade futura. As consequências variam da redução da produtividade até aumento da criminalidade, elevando os custos para os jovens, para a economia e a sociedade como um todo, atingindo áreas como saúde, educação, segurança, bem como para a previdência e assistência social.

Os efeitos diretos e indiretos decorrentes disso somando-se à relativa escassez de dados tornam a mensuração de tais custos uma tarefa bastante complexa e não isenta de suposições e simplificações para tornar-se exequível. Tendo em vista essas limitações, este estudo restringiu-se à análise dos principais custos correntes para subgrupos específicos de nem-nem: inativos e desempregados. Apesar das estimativas obtidas neste estudo não esgotarem todos os custos atrelados ao fenômeno dos nem-nem, elas permitem inferir um limiar inferior que pode auxiliar no desenho de políticas públicas que objetivem reduzir o número de jovens nem-nem.

Os resultados revelaram que os custos econômicos associados aos nem-nem perfazem pelo menos $0,6 \%$ do PIB. São mais de R $\$ 36$ bilhões que poderiam ser investidos em diversas áreas sociais que implicariam a melhoria de bem-estar de uma parcela substancial da sociedade, dos quais se destaca o subgrupo dos inativos, principalmente das mulheres.

Esses elevados custos destacam a necessidade de intervenções políticas que melhorem a transição dos jovens entre a escola e o mercado de trabalho e que visem reengajar efetivamente os jovens nem-nem. Contudo o foco somente nesse grupo de jovens não resolverá o problema, haja vista que é preciso examinar a fonte desse problema. Intervenções precoces ainda durante o período na escola podem fazer diferença. Assim, torna-se um desafio para os gestores públicos prevenir ou evitar a ascensão da trajetória de jovens nem-nem no país.

Ficou demonstrado que estratégias de investimento para dar suporte aos jovens em risco de desengajamento no mercado de trabalho podem ser um efetivo meio de reduzir os gastos públicos totais. Falhas em tais investimentos implica severos danos de curto, médio e longo prazo para a economia e a sociedade.

\section{REFERÊNCIAS BIBLIOGRÁFICAS}

AGUILA, E. et al. (2013) "Pobreza y Vulnerabilidad en México: El caso de los Jóvenes que no Estudian ni Trabajan”, Corporación Rand, 51 p. (Working Paper - WR - 991).

BALAN, M. (2016) "Economic and Social Consequences Triggered By The Neet Youth", Knowledge Horizons, Economics, 8(2): 80.

BELL, D. NF; BLANCHFLOWER, D. G. (2011) "Young people and the Great Recession", Oxford Review of Economic Policy, 27(2): 241-267.

COLES, B. et al. (2010) "Estimating the life-time cost of NEET: 16-18 year olds not in Education, Em- 
ployment or Training”, Research Undertaken for the Audit Commission. Hg. v. University of York, v. 15, p. 2012. Disponível em: http://www. york.ac.uk/inst/spru/research/pdf/NEET.pdf,

CORSEUIL, C. H.; SANTOS, D. D.; FOGUEL, M. N. (2017) "Decisões críticas em idades críticas: A escolha dos jovens entre estudo e trabalho no Brasil e em outros países da América Latina”, Ipea, 46 p. (Texto para Discussão, 797). Disponível em: http://www.ipea.gov.br. Acesso em: 15 jul. 2017.

CORSEUIL, C. H. et al. (2013) A rotatividade dos jovens no mercado de trabalho formal brasileiro, Nota Técnica - Mercado de Trabalho, IPEA.

EUROPEAN FOUNDATION FOR THE IMPROVEMENT OF LIVING AND WORKING CONDITIONS et al. (2012) "NEETs Young people not in employment, education or training: Characteristics, costs and policy responses in Europe”, Publications Office of the European Union.

FERGUSSON, D. M.; HORWOOD, L. J.; WOODWARD, L. J. (2001) "Unemployment and psychosocial adjustment in young adults: causation or selection? Social Science \& Medicine, 53(3): 305320.

GERDTHAM, Ulf-G.; JOHANNESSON, M. (2003) "A note on the effect of unemployment on mortality", Journal of Health Economics, 22(3): 505-518.

GODFREY, C.; BRADSHAW, J.; HUTTON, S. (2002) "Estimating the cost of being'not in education, employment or training at age 16-18", Great Britain, Department for Education and Skills.

GOLDSMITH, A. H.; VEUM, J. R.; WILLIAM, D. (1996) “The impact of labor force history on self-esteem and its component parts, anxiety, alienation and depression", Journal of Economic Psychology, 17(2):183-220.

GREGG, P. (2001) "The impact of youth unemployment on adult unemployment in the NCDS", The Economic Journal, 111(475): 626-653.

GREGG, P. \& TOMINEY E. (2005) “The wage scar from male youth unemployment”, Labour Economics, 12.

INSTITUTO BRASILEIRO DE GEOGRAFIA E ESTATÍSTICA (2016), “Síntese de Indicadores Sociais".

MALONEY, T.; PARAU (2004) "Isolating the scarring effects associated with the economic inactivity of youth in New Zealand: evidence from the Christchurch health and development study", Report to the Labour Market Policy Group.

MENEZES FILHO, N. A.; CABANAS, P. H. F.; KOMATSU, B. K. (2013). "A condição "nem-nem” entre os jovens é permanente", São Paulo: Insper.

MROZ, T.; A.; SAVAGE, T. H. (2006) “The long-term effects of youth unemployment", Journal of Human Resources, 41(2): 259-293.

MONTEIRO, J. (2013) “Quem são os jovens nem-nem?: Uma análise sobre os jovens que não estudam e não participam do mercado de trabalho". Rio de Janeiro: FGV - IBRE, Texto para Discussão 34.

PETCU, S. V.; POPA, I. L. (2015) “Structural Funds and Romanian Neets 2007-2013", Young, 3(1), p. 7.

PACHECO, G.; DYE, J. (2014) "Estimating the cost of youth disengagement in New Zealand”, New Zealand Journal of Employment Relations (Online), 38(2): 47.

ROSENBAUM, P. R.; RUBIN, D. B. (1983) “The central role of the propensity score in observational studies for causal effects”, Biometrika, p. 41-55.

SAMOILENKO, A.; CARTER, K. (2015) "Economic outcomes of youth not in education, employment or training (NEET)", New Zealand Treasury.

SIQUEIRA, R.B.; NOGUEIRA, J. R. B.; SOUZA, ES (2012). O sistema tributário brasileiro é regressivo?

VENTURI, G.; TORINI, D. (2014) Transições da escola para o trabalho dos jovens homens e mulheres no Brasil.

WU, D.; WU, Z. (2012) “Crime, inequality and unemployment in England and Wales”, Applied Economics, 44(29): 3765-3775. 


\section{APÊNDICE}

Gráficos 3(a) antes e depois do pareamento:

Nem-nem inativos

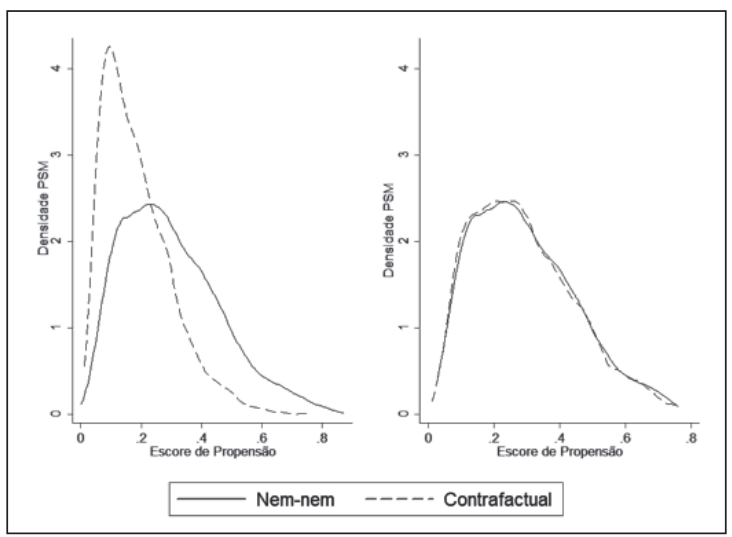

Fonte: Elaboração própria com base nos dados da PNAD e dos resultados obtidos com o PSM.

Gráficos 3(b) antes e depois do pareamento:

Nem-nem desempregados

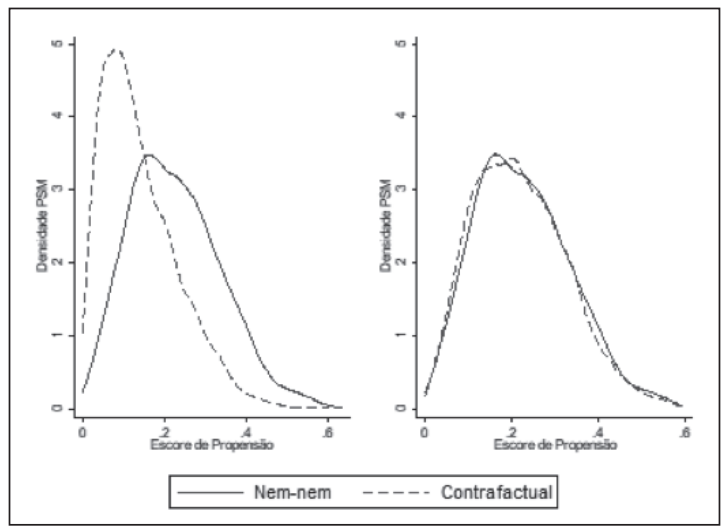

Fonte: Elaboração própria com base nos dados da PNAD e dos resultados obtidos com o PSM. 